\title{
Acessibilidade e experiência estética: um trabalho com mulheres em situação de vulnerabilidade
}

\author{
Flavia Liberman, Viviane Maximino
}

Departamento de Saúde, Clínica e Instituições, Universidade Federal de São Paulo - Santos, SP, Brasil.

\begin{abstract}
Resumo: Este artigo relata os resultados parciais da pesquisa Cartografias Femininas e expõe estratégias utilizadas no acompanhamento de mulheres que vivem em região de alta vulnerabilidade da cidade de Santos, SP. Cenas de trabalho e trechos do diário de pesquisa abordam o conceito de acessibilidade em suas múltiplas facetas, a partir das diversas categorias associadas às barreiras arquitetônicas, físicas, geográficas, comunicacionais, metodológicas, instrumentais e atitudinais. Explora ainda o conceito de experiência estética, afirmando sua importância nos processos de cuidado de mulheres marcadas por este território e seus problemas. Articulando diversos atores: docentes, estudantes e mulheres, apresenta o Método da Colheita, tecnologia que favorece o acesso à práticas corporais e estéticas e a um espaço de arte e cultura, para que a experiência estética possa acontecer. Por meio de proposições feitas aos participantes aposta-se na possibilidade de colocar as pessoas em movimento, desencadeando processos de criação, engendrando novos territórios existenciais e reinventando vidas, objetivos essenciais nas práticas de terapia ocupacional.
\end{abstract}

Palavras-chave: Terapia Ocupacional, Experiência Estética, Vulnerabilidade, Cultura.

\section{Accessibility and aesthetic experience: work with women in vulnerability situation}

\begin{abstract}
This article reports partial results of a research called Cartografias Femininas and exposes strategies used in the care of women that live in a high-vulnerability region of the city of Santos, SP. Work scenes and excerpts of research diaries address the concept of accessibility in its multiple facets from the various categories associated with the architectural barriers, physical and geographical, communicative, methodological and instrumental, and attitudinal. Also explores the concept of aesthetic experience, stating its importance in the care process of women marked by this territory and its problems. Articulating different actors: teachers, students and women, presents the Método da Colheita (Harvest Method), technology that facilitates access to physical and aesthetic practices and a space of art and culture, so that the aesthetic experience can take place. Through statements made to the participants bet on the possibility of putting people in motion, triggering processes of creation, engendering new existential territories and reinventing lives. These are main targets of the occupational therapy pratices.
\end{abstract}

Keywords: Occupational Therapy, Aesthetic Experience, Vulnerability, Culture. 
"Liberdade é pouco.

O que desejo ainda não tem nome" (LISPECTOR, 1980, p. 50.)

Quarta-feira, dia de ir a campo no módulo Trabalho em Saúde (TS) ${ }^{1}$, vamos para a região noroeste de Santos. Quando entramos na van já começa o "noticiário": hoje a D. Marta ${ }^{2}$ vai ao médico, mas a Ditinha estará lá. D. Eufrazia não vai, está com dor no pé e parece muito deprimida de novo. D. Marina mudou de casa e não sabemos onde é. O André, que ficou como referência de D. Soraia, não veio hoje, e D. Francisca sumiu: não tem telefone e não conseguimos localizar. Os alunos, de mapa em mãos e com alista de mulheres devem estar bem despertos. Acostumados a dormir nos trajetos, têm agora que exercitar a presença, a atenção (Diário de anotações ${ }^{3}$, LIBERMAN, 2015).

\section{Introdução e justificativa}

Esse artigo relata os resultados parciais da pesquisa Cartografias Femininas: açôes territoriais junto às mulheres da região noroeste de Santos ${ }^{4}$ e discute como construir vias de acesso (geográfico, relacional, a si mesmo) para que pessoas, atravessadas pelo território e seus problemas: medicalização, pobreza, violência, escassez de oportunidades culturais, etc. possam vivenciar experiências estéticas. Afirma também a importância das mesmas na ampliação das possibilidades de afetar e ser afetado, de sentir-se vivo, a partir do contato e das conexóes com os outros e seus mundos.

A discussão sobre acessibilidade é bastante complexa. Para o senso comum, acessibilidade está diretamente associada às pessoas com deficiência física e sensorial socialmente reconhecidas como tal. No entanto, apesar de avanços na legislaçãos

[...] possuir algum tipo de deficiência em um país marcado por grandes contrastes e desigualdades sociais [...], significa estar mais distante de receber um atendimento de saúde com qualidade, uma educaçáo de bom nível e uma digna oportunidade de trabalho no mercado formal. Um grande desafio e inúmeros obstáculos devem ser enfrentados ainda pela pessoa com deficiência, quando busca atividades relacionadas ao lazer e ao turismo (SANSIVIERO; DIAS, 2005, p. 4).

Para esta autora, acessibilidade está associada também à prática do acolhimento e da hospitalidade, ações que possuem forte vínculo social, pois se caracterizam como atividades desempenhadas por pessoas para outras pessoas que proporcionam relaçôes interpessoais e sociais.

O conceito de acessibilidade assenta-se na concepção e no desenvolvimento de soluçóes seguras e capazes de serem utilizadas por todos, ou por um maior número possível de cidadáos, evitando sempre que possível a necessidade de segregaçáo. O desenvolvimento de soluções específicas deve dar lugar a soluçōes seguras e universais, restringindo-se a soluçóes especiais apenas onde exista impossibilidade de integração. Acessibilidade é uma característica que define (quantifica e qualifica) a facilidade de acesso entre bens, pessoas e atividades e objetiva-se no encontro com a natureza e com o "outro", na descoberta de novas realidades e na fruição da urbanidade. Não se trata, portanto de melhorar somente a prática, os regulamentos, mas sim operar uma transformação cultural na abordagem da questáo da acessibilidade como tema central da equidade e democracia (SEIXAS; ALVES, 2006).

Sassaki (2003) ao escrever sobre acessibilidade em logradouros turísticos indica que existem seis tipos diferentes de barreiras.

As arquitetônicas, que se referem às barreiras físicas e geográficas; as comunicacionais, que impedem a comunicação entre as pessoas; as metodológicas e instrumentais quando os métodos, técnicas e instrumentos para a realização de ações e atividades exigem determinadas características dos participantes que excluem os demais; as programáticas que são as barreiras embutidas em políticas públicas, legislaçóes, normas, etc.; e as atitudinais provocadas por preconceitos, estereótipos, estigmas e discriminaçóes nos comportamentos da sociedade (SASSAKI, 2003, p. 35).

Para este autor, somente após a remoção das chamadas barreiras arquitetônicas é que a sociedade, como um todo, através da convivência, poderá identificar as demais barreiras existentes. Percebe-se que não basta a possibilidade de acesso geográfico às ofertas sociais. As mulheres que atendemos enfrentam dificuldades relacionadas à sua mobilidade reduzida, não só por aspectos físicos que poderiam ser compensados pela superação desta barreira. A região violenta causa medo, há solidão, isolamento e diminuição do pulso vital (KELEMAN, 1992) ${ }^{6}$, Há o desenraizamento cultural e a pouca possibilidade de viver experiências que as desloquem da situação de sobrevivência e resposta aos problemas cotidianos para a alegria 
como ampliação de mundos e produção de outros modos de subjetividade. Todos estes aspectos estáo associados às dificuldades de chegar e aproveitar recursos de arte e cultura, que já são bastante escassos no território.

Considerando que um dos principais objetivos da intervenção em terapia ocupacional é a ampliação da possibilidade de inclusão e participação social e que esta acontece, não como abstração, mas sim como ação concreta no mundo, justifica-se a preocupação com a acessibilidade em seu sentido amplo, incluindo sua dimensão estética, e a busca de estratégias para viabilizá-la.

\section{Objetivo}

Um dos objetivos da pesquisa, abordado neste artigo, é a criação e a verificação da efetividade de propostas de intervenção que ampliem o acesso de pessoas à possibilidade de experiências estéticas.

\section{Metodologia}

Tomando como desafio o caráter inventivo da ciência que a coloca em

[...] constante movimento de transformaçáo, não apenas refazendo seus enunciados, mas criando novos problemas que exigem práticas originais de investigação (BARROS; KASTRUP, 2009, p. 55)

são mobilizadas nesta pesquisa diferentes estratégias metodológicas que a configuram como uma pesquisa- intervenção. Nesta perspectiva, o pesquisador investiga uma determinada situação, ao mesmo tempo em que se mantém no campo em contato direto com as pessoas e seu território existencial, modificando e sendo modificado pela experiência (BARROS; KASTRUP, 2009). Segundo Rocha e Aguiar (2003, p. 67)

[...] o processo de formulação da pesquisaintervenção aprofunda a ruptura com os enfoques tradicionais de pesquisa e amplia as bases teórico-metodológicas das pesquisas participativas, enquanto proposta de atuação transformadora da realidade sociopolítica, já que propóe uma intervenção de ordem micropolítica na experiência social.

A pesquisa em curso, acompanha e analisa as estratégias de intervenção que são desenvolvidas no acompanhamento de mulheres para que estas consigam acessar semanalmente um espaço onde são oferecidas atividades de arte e cultura.
Estas estratégias, desenvolvidas na atividade prática de alunos de graduação e seus docentes, são descritas detalhadamente nos diários de campo das pesquisadoras. Este material é examinado utilizando-se análise de discurso com levantamento dos temas mais prevalentes.

Neste artigo será abordado apenas o tema da acessibilidade.

\section{Resultados e discussão}

\subsection{O Método da Colheita}

Os diários de campo das pesquisadoras trouxeram inúmeras vezes o tema da acessibilidade, tanto no que diz respeito às suas inúmeras barreiras quanto às estratégias de superação das mesmas inventadas ao longo da pesquisa.

Uma das estratégias utilizadas é o que chamamos de Método da Colheita. Trata-se de buscar as mulheres em suas casas ou em pontos determinados para participarem do Grupo de Mulheres que acontece no Instituto Arte no Dique ${ }^{8}$.

O Arte no Dique está localizado em uma construção bonita, ancorada praticamente em cima de um lixão o que, além de criar um estranhamento, revela a proposta de acessibilidade que estamos discutindo aqui. Com janelas, transparências e aberturas parece nos falar da porosidade da proposta em receber os moradores da região. Pode indicar também a disponibilidade do equipamento em trabalhar com diversos parceiros, entre eles a universidade, no acesso destas pessoas, oferecendo espaço-tempo e condiçóes para que a proposta ali se realize.

O rompimento de barreiras arquitetônicas e físicas do território não seria suficiente para a manutenção desta proposta se náo fosse o trabalho vincular, permanentemente em construção, realizado por todos os envolvidos. O acompanhamento das mulheres inicia-se muito antes da chegada no Dique. A recepção realizada pelos alunos, desde a ida as casas ou pontos de encontro, as conversas no caminho e a entrada na van criam rapidamente um clima de acolhimento e afeto que é determinante para a continuidade e permanência das mulheres no projeto (LEANDRO, 2014). Este trabalho cria um acesso que rompe barreiras comunicacionais pela aproximação dos alunos às mulheres e $\mathrm{a}$ alguns pontos da regiāo, atravessado por condiçóes ambientais nem sempre favoráveis (chuvas, possibilidade de enchente, situaçôes de violência, entre outras).

Outra barreira fundamental que precisa ser rompida é a atitudinal que, neste caso, pode se referir a não 
percepção de que existem muitos mundos possíveis (CASTRO, 2002) e diferentes que convivem nesta situação. Rompem-se preconceitos em relação à vida de cada mulher acompanhada e suas limitações e percebem-se potencias, produzindo uma ampliação de perspectivas que só é possível por estarmos todos juntos tecendo a cada vez um encontro que possa ser significativo. Isto denuncia uma intenção que também faz parte da remoção de barreiras metodológicas e instrumentais: desenvolver um estado de presença e prontidão para captar tudo aquilo que surge nestes encontros. Prontidão e presença para mergulhar no acontecimento ao mesmo tempo em que se situa na borda, observando, sentindo e pensando.

Um trabalho artesanal, diz a professora. Aqui se aprende perseverança, paciência, a atenção ao pequeno. Aqui se faz um trabalho corpo a corpo (Diário de anotaçóes, LIBERMAN, 2015).

O sentido do corpo a corpo é também literal. $\mathrm{O}$ sol é forte, o trajeto depois do almoço sacudindo na van afeta os corpos. A paisagem da região já nos força um deslocamento das salas de aula para a rua, para outra realidade. Esta mudança atitudinal é dada pela vivencia do encontro. Acessibilidade aqui, para além de ser um direito é principalmente aquilo que pode possibilitar que algo aconteça. Náo se trata apenas do acesso concreto das pessoas em relação a sua mobilidade espacial nem de disponibilizar ofertas, trata-se de promover possibilidades para os encontros consigo mesmo, com as pessoas e com coisas ${ }^{9}$.

Produzir ou favorecer os deslocamentos tanto geográficos quanto subjetivos. Lidar com o medo, náo se deixando paralisar. A van parando no local do tráfico, a negociação com o motorista para estacionar em local que náo bloqueie a visibilidade de uma possível visita da polícia. Uma aposta, ir apesar do medo (Diários de pesquisa, LIBERMAN; MAXIMINO, 2015a).

O medo de sair de casa também é um obstáculo ao acesso e circulação na região. Este medo também está em nós. A questão é como evitar que ele nos paralise. Há também uma aposta de que a nosso vínculo com estas mulheres permita nossa presença ali, naquela área de risco. Aqui, as mulheres são a nossa conexẫo e via de acesso ao/no território. Território que também oferece experiências e aprendizado para todos.

Eulália teve um AVC e anda com bengalas, Lucia tem artrose, Fernanda esteve internada em um hospital psiquiátrico, mora longe e ainda precisa de estímulo para sair. Mariquita aproveita que a vizinha está indo ao grupo e entra na van também, dizendo: estou cansada de ficar sentada em casa. Estas duas convidaram uma terceira, muito deprimida com a perda de dois filhos jovens na violência do bairro (Diário de anotaçóes, LIBERMAN, 2015).

A partir deste posicionamento atento e aberto ${ }^{10}$ e da mobilização de alunos e docentes foi possível, por exemplo, o empréstimo semanal de um degrau de um laboratório da universidade para que Lucia pudesse subir e descer da van com mais independência. No encontro com a realidade e na sensibilizaçáo que ela promove, é possível criar uma estratégia para superação de uma barreira arquitetônica.

Mas há também outras barreiras, por exemplo a que vamos denominar de barreira da mesmice (do pensamento e da ação), aquelas que impedem deslocamentos da subjetividade: trata-se de percorrer os atalhos, evitar a grande avenida hegemônica que dá acesso àquilo que nem sempre é desejável, rompendo cristalizaçôes e modos de existência despotencializados.

Telma tem vários corpos, aquele medicalizado, anestesiado, mas também um corpo sutil e sensível, passível de afetar e ser afetado. A grande avenida pode levar por exemplo, ao CAPS, mas como criar atalhos, tornar outros caminhos acessíveis? Como abrir acesso, ativar, estes outros corpos? Como favorecer que um corpo medicalizado, amedrontado ou paralisado, possa usufruir da arte como direito, viver a experiência estética e a participação na cultura? Além do CAPS, o Arte no Dique. Um deslocamento (Diários de pesquisa, LIBERMAN; MAXIMINO 2015a)

\subsection{O dispositivo grupal e experiência estética}

Sabe... do mesmo jeito que você cuida do seu cabelo, fazendo chapinha, você vai poder cuidar de você por dentro (Fala de Soraia, participante do grupo).

O Instituto Arte no Dique tinha como população-alvo principal crianças e jovens mas com a nossa presença passa a incorporar as mulheres e sua circulação. Isto é um indicativo de ampliação no acesso e reflete a superação de uma barreira atitudinal com relação à determinada faixa etária e problemática. Pessoas mais velhas ou com restriçóes podiam participar mas não havia propostas voltadas para elas. Isso indica que o acesso tem que ser construído. A entrada do 
profissional terapeuta ocupacional, tradicionalmente vinculado ao campo da saúde e da população trazida por ele, em um espaço que não tem como objetivo central tratar a doença, produz um enfrentamento das barreiras atitudinais abrindo um campo problemático. A proposta do grupo, em um espaço de arte e cultura intensifica uma mudança de foco, tensionando o conceito de saúde/doenç ${ }^{11}$, e indica a necessidade de um trabalho interprofissionalidade na perspectiva da intersetorialidade. Outros deslocamentos.

As mulheres que acompanhamos trazem para os encontros suas histórias, desejos, questóes e dificuldades. Utilizando práticas corporais e estéticas ${ }^{12}$ desloca-se a intervenção do predomínio da linguagem verbal, geralmente utilizada para coletar informaçóes, identificar diagnósticos, passar prescriçóes, educar, etc., para outras linguagens e experiências.

Iniciamos com a proposta de falar o nome e fazer um gesto, que será repetido pelo grupo. Neste momento reconheço a singularidade do outro e ao mesmo tempo, a presença do outro em mim. Não estou mais sozinho (Diário de anotaçôes, LIBERMAN, 2015).

As marcas presentes nos participantes convidam ao movimento, ao prosseguir. Acessando a vida do outro, acesso minha vida e ao mesmo tempo desloco-me de mim mesmo. Estar em grupo amplia a chance de acionar nos participantes o que Dewey (2010) chama de experiência estética.

A experiência estética emerge na vida cotidiana, mas ela se define entretanto como uma experiência especial que faz com que a vida não se apresente como uma corrente homogênea e uniforme de fatos banais (KASTRUP, 2010, p. 39).

A experiência estética tem algumas qualidades: é marcante, não se dissipa nem é facilmente esquecida, possui unidade sendo que suas partes constituintes são reunidas sem emendas ou vazios e além disso, esta unidade inclui de modo indistinto as dimensóes emocional, prática e intelectual que só a posteriori podem ser separadas. A emoção é uma qualidade da experiência, a experiência estética é emocional (DEWEY, 2010 apud LIBERMAN; MAXIMINO, 2015b, p. 121).

A cada vez não se sabe o que vai acontecer no encontro.

O inusitado: Onde está Mariquita? Ela não tem vindo, vamos passar na casa dela para ver o que está acontecendo? Ela estava dormindo, doente há vários dias. Estava bem fragilizada, despenteada, com as roupas mal cuidadas.
Escolhemos um outro vestido. $\mathrm{O}$ importante para nós era que ela pudesse se deslocar e ser cuidada, mesmo que permanecesse em silencio (Diário de anotaçóes, LIBERMAN, 2015).

Presenciar a cena da aluna ajudando esta senhora em uma situação íntima, delicadamente triste constituiu-se em uma experiência estética para todos os envolvidos. Experiência que pôde acontecer porque houve encontro.

Há também em nosso trabalho um transbordamento espaço-temporal. Antes de ir a campo há contatos telefônicos. Já na van vamos nos mobilizando com as notícias de cada uma, elas já são uma presença viva em nós. Trata-se, portanto de

Criar estratégias de aproximação com o outro, de torná-lo presença viva em nós. Nossa presença ali mobilizava, fazia acontecer nos corpos, sensaçóes, ideias, contraçóes e retrações, pulsos dinâmicos e diversos (Diários de pesquisa, LIBERMAN; MAXIMINO, 2015a).

O desejo de que o encontro se dê contagia o entorno favorecendo a realização do projeto. Isto se expressa na preparação do ambiente, na colocação das cadeiras em roda, na escolha e elaboração das dinâmicas, no trabalho conjunto com os outros profissionais do serviço, etc. facilitando o acesso às proposiçóes. Outra característica importante é que meios e fins se coadunam, isto é, não estáo dissociados. Dewey (2010) "[...] trazendo aqui a dimensão do processo como fundamental para o acontecimento da experiência" (DEWEY, 2010, p. 355).

No Grupo de Mulheres busca-se proporcionar aos participantes possibilidades de experiências estéticas apostando que estas podem produzir movimento e inventar outras realidades, instaurando processos de criação, engendrando novos territórios existenciais. Os participantes são catalizadores e também testemunhas das experiências vividas. Quando Telma gargalha com uma careta, ativa-se um outro corpo: um corpo lúdico. Quando Eulália canta e dá risada, ela não é somente uma mulher que teve um Acidente Vascular Encefálico.

O que te alegra? A busca pela alegria ${ }^{13}$ (SPINOZA, 2007), mesmo em fiapos é o que norteia nossas açóes no grupo. A vida mais viva. Ativar e qualificar momentos de alegrias vividas no passado, possibilitando alegrias no presente e apostando em desejos de alegria, como possibilidade e virtualidade. Fernanda mostra seus panos de prato com um discurso animado, reconhecendo e sendo reconhecida por seus talentos. Uma aluna traz uma caixa de origamis e desperta 
curiosidade; uma estagiaria estrangeira, contanto sobre seu país, faz acontecer uma dança tradicional.... Seguimos dando materialidade às ideias: surge a vontade de ir ao horto, ir ao cinema, ir à praia, transitar. Acesso aqui diz respeito ao inventar e construir trilhas para dar concretude aos sonhos. Busca-se criar um território propício a surpresa, ao acolhimento do inesperado e ao acionamento de movimentos inventivos (KASTRUP, 2010).

Telma chega muito emocionada e perturbada. Seguro em suas mãos. Juliana fica atrás dela oferecendo seu corpo para sustentá-la, no apoio, e Patrícia "regava-a", trazendo copos d'água (Diário de anotaçóes, LIBERMAN, 2015).

A experiência estética não é algo entretêm ou que é divertido, mas aquela que produz sensaçóes intensas por vezes trazendo sofrimento. A cena com Telma ilustra esta situação. Por vezes, a intensidade pode ser excessiva para aquele corpo e produzir, ao invés de um estado de experiência, o reflexo do susto, o que faz com que o sujeito afaste-se do mundo e de si (KELEMAN,1992). Para evitar que determinada técnica utilizada transforme-se em barreira à experiência é necessário a percepçáo sutil dos processos, o cuidado e o modo como se acompanham os acontecimentos. A construção de um ambiente confiável, sustentado por vínculos e um respeito pelo tempo formativo favorecem que a experiência possa ser incorporada e atualizada para novas e outras situaçôes ampliando a acessibilidade à experiência estética.

Mas, o que mais favorece a experiência estética? O cultivar-se para ela. Kastrup (2010) citando uma entrevista de Deleuze, diz que ele não procura os espaços de arte e produçáo cultural para ter mais cultura, mas para cultivar-se; não acredita na cultura em si, mas nos encontros, não só com pessoas mas, sobretudo com as coisas. Portanto, cultivar-se pode ser compreendido como abrir-se aos encontros, como um exercício de atenção à espreita às possibilidades de encontro (LIBERMAN; MAXIMINO, 2015b, p. 122) "[...] ir em busca de encontros, experiência e aprendizagem e não de informaçáo ou de um saber pronto para ser absorvido ou consumido". "Portanto, não basta estar em um equipamento de cultura para se favorecer a acessibilidade estética" (KASTRUP, 2010, p. 39).

Circular por um chamado espaço de cultura não garante nem a acessibilidade nem a experiência estética no entanto, estar na ONG Arte no Dique, propicia o uso de práticas artísticas. A arte, assim como o lúdico, por suas características de invenção, não produtivismo, não mecanização e integração do processo ao produto é fruição, aproveitamento e consumação em si mesma, favorecendo as experiências estéticas. A atividade artística que gera uma experiência estética náo se define por produzir objetos decorativos nem por introduzir no cotidiano um traço especial de beleza (DEWEY, 2010). Em contrapartida, seus inimigos são a burocratização da vida, o automatismo e a idealização da ideia de arte e estética, acessíveis apenas para alguns e segundo padróes validados culturalmente. Em nosso caso, podemos relacionar os inimigos da experiência estética com as barreiras atitudinais, comunicacionais, metodológicas e instrumentais.

A experiência estética está associada a produção de desejo intensificado pelo próprio ato artístico e não dado por antecipação. Em oposição aos processos mecânicos, a arte desenrola-se de maneira inusitada e "[...] o suspense, na arte, é um apetite que aumenta a partir daquilo com que é alimentado" (KAPLAN apud DEWEY, 2010, p. 28).

No grupo fazemos um convite ao olhar-se, ao conhecer-se, ao reinventar-se no encontro com o outro e com as proposiçóes sugeridas. A experiência estética acontece em momentos de intensificação da experiência: quando, por exemplo, testemunhamos o choro de Telma ou ouvimos atentamente narrativas de Fernanda, maltratada em um hospital psiquiátrico, mas também em momentos de cantos e danças partilhadas, acontecimentos estes que nos tocam e que nos fazem sair diferentes dali.

\section{Considerações finais}

A pesquisa-intervenção Cartografias femininas: açôes territoriais junto as mulheres da região Noroeste de Santos, tem oferecido espaço importante para a reflexão sobre diferentes temáticas que envolvem o cuidado às mulheres daquela regiâo. Ao examinar as açóes realizadas: Método da Colheita, uso do dispositivo grupal e proposta artísticas e corporais, pode-se discutir o conceito de acessibilidade, ampliando-o e introduzindo o tema da acessibilidade estética como processo em direção aos objetivos da terapia ocupacional.

Ao considerarmos as barreiras comunicacionais, metodológicas, programáticas, técnicas e culturais, além das já tradicionais barreiras arquitetônicas ou físicas, abordamos também a necessidade de criarmos outros tipos de tecnologia para a ampliação de práticas de acessibilidade, dando visibilidade e incluindo estas mulheres no conjunto de pessoas 
que necessitam de acessibilidade, o pode pressionar políticas públicas de acesso universal.

No contato com cada uma delas verifica-se que a ausência de transporte adaptado, por exemplo, é uma pequena parte das dificuldades de acesso. Estas dizem respeito a uma vida que está restrita por diversos motivos. Além disso, pouco se valoriza a necessidade de acessibilidade para usufruir da arte e da cultura que podem reunir e disponibilizar aquilo que é direto de todos: a alegria, a pertença e o reconhecimento, a emoção, a mobilização, o encontro. Um dos resultados desta proposta foi ter colocado esta questão em pauta para os serviços envolvidos no projeto de acompanhamento destas mulheres.

Especificamente avaliamos também que o Método da Colheita é potente, mas apresenta fragilidades, pois depende neste momento de recursos humanos e materiais disponibilizados apenas pela universidade, exigindo investimento continuo.

O tema da acessibilidade merece maior atenção para que seja uma preocupação dos profissionais dos serviços e cidadãos, no que se refere aos seus direitos e possibilidades de ação. É necessário formar profissionais sensíveis a este tema que possam perceber e valorizar a importância de estratégias desta natureza, ampliando o conceito de saúde, desenvolvendo um pensamento complexo e singular, aproveitando os recursos da regiâo e exercitando a criatividade.

\section{Agradecimentos}

Agradecemos a Profa. Dra Marina Guzzo que coordena o Grupo de Mulheres no Arte no Dique junto com a Profa. Dra Flavia Liberman.

\section{Referências}

BARROS, L. P.; KASTRUP, V. Cartografar é acompanhar processos. In: PASSOS, E.; KASTRUP, V.; ESCÓSSIA, L. (Org.). Pistas do método da cartografia: pesquisaintervenção e produção de subjetividade. Porto Alegre: Sulina, 2009. p. 52-75.

CAPOZZOLO, A.; CASETTO, S.; HENZ, A. (Org.). Clínica comum, itinerários de uma formação em saúde. São Paulo: Hucitec, 2013.

CASTRO, E. V. O nativo relativo. Maná, Rio de Janeiro, v. 8, n. 1, p. 113-148, 2002.

DEWEY, J. A arte como experiência. São Paulo: Martins Fontes, 2010.

G1: SANTOS E REGIĀO. Instituto Arte no Dique lançará filial em Salvador. Santos, 2014. Disponível em: $\quad<$ http://g1.globo.com/sp/santos-regiao/noticia/2014/07/instituto-arte-no-dique-lancara-filial-emsalvador.html>. Acesso em: 21 maio 2015.
KASTRUP, V. O Funcionamento da atenção no trabalho do cartografo . Psicologia e Sociedade, Porto Alegre, v. 19, n. 1, p. 15-22, 2007.

KASTRUP, V. Experiência estética para uma aprendizagem inventiva: notas sobre acessibilidade de pessoas cegas a museus. Informática na educação: teoria e prática, Porto Alegre, v. 13, n. 2, p. 38-45, 2010.

KELEMAN, S. Anatomia emocional. São Paulo: Summus Editorial, 1992.

LEANDRO, N. Colhendo e acolhendo: experiências de estudantes de Terapia Ocupacional em um grupo de mulheres na regiáo noroeste. 2014. [s.p]. Trabalho de Conclusão de Curso (Graduação em Terapia Ocupacional) - Universidade Federal de São Paulo, Santos, 2014.

LIBERMAN, F. Diário de anotaçôes. Santos, 2015. (Arquivo pessoal).

LIBERMAN, F.; MAXIMINO, V.S. Diários de pesquisa. Santos, 2015a. (Arquivo pessoal).

LIBERMAN, F; MAXIMINO, V. Planos grupais e experiência estética: friccionando ideias, emoçōes e conceitos. In: MAXIMINO, V.; LIBERMAN, F. (Org.). Grupos e terapia ocupacional, formação, pesquisa e açōes. São Paulo: Summus Editorial, 2015b. p. 115-127.

LISPECTOR, C. Perto do coração selvagem. Rio de Janeiro: Editora Nova Fronteira, 1980.

MAXIMINO, V.; PETRI, E. C.; CARVALHO, A. O. C. A compreensão de saúde para o Método Terapia Ocupacional Dinâmica. Revista do CETO, São Paulo, ano 13, n. 13, p. 34-40, 2012.

MÉTODO. In: MICHAELIS: Dicionário de Português Online. São Paulo: Editora Melhoramentos, 2009. Disponível em: <http://michaelis.uol.com.br/ moderno/portugues/index.php?lingua=portuguesportugues\&palavra $=\mathrm{m} \%$ E9todo $>$. Acesso em: 13 maio 2016.

ROCHA, M. L.; AGUIAR, K. F. Pesquisa-intervençáo e a produção de novas análises. Psicologia: ciência e profissão, Brasília, v. 23, n. 4, p. 64-73, 2003.

SANSIVIERO, S.; DIAS, C. M. M. Hotelaria e acessibilidade. Turismo - Visão e Ação Balneário, Camburiú, v. 7, n. 3, p. 439-453, 2005.

SASSAKI, K. R. Inclusão no lazer e no turismo: em busca da qualidade de vida. São Paulo: Áurea, 2003.

SEIXAS, J.; ALVES, M. Mobilidade e acessibilidade: conceitos e novas práticas. Revista Indústria e Ambiente, Porto, v. 55, p. 12-14, 2006. Disponível em: <http://pascal.iseg.utl.pt/ -ppereira/DobrarEsquina/main/Artigos/ Tertulia_Janeiro/JSeixas_e_MAlves/8_Industria_e_Ambiente_mob_vs_acess.pdf>. Acesso em: 21 maio 2015.

SPINOZA, B. Ética. Belo Horizonte: Autêntica, 2007. 


\section{Contribuição dos Autores}

Flavia Liberman e Viviane Maximino participaram igualmente da concepção e redação do texto. Ambas as autoras aprovaram a versão final do texto.

\section{Notas}

${ }^{1}$ O projeto político pedagógico da Universidade Federal de São Paulo, Baixada Santista (UNIFESP, BS), indica a educação interprofissional e o aprendizado em cenários reais como estratégias na formação de profissionais de saúde. No eixo comum Trabalho em Saúde, os estudantes dos vários cursos desenvolvem atividades em regióes de maior vulnerabilidade social acompanhados de professores. Ver: Capozzolo, Casetto, Henz (2013).

${ }^{2}$ Os nomes são fictícios para preservar a identidade das participantes.

${ }^{3}$ Neste artigo serão citados trechos de material produzido pela pesquisa: Diário de Anotaçôes, referentes a anotações feitas em campo pela pesquisadora 1 e Diários de pesquisa, feitos pelas pesquisadoras 1 e 2 em reunióes de discussão e análise dos dados.

${ }^{4}$ A pesquisa Cartografias Femininas: açôes territoriais junto às mulheres da regiāo Noroeste de Santos, em andamento, objetiva investigar açôes realizadas com mulheres que procuram espaços de cuidado, utilizando equipamentos e articulações disponíveis no território que apresenta alto índice de vulnerabilidade.

${ }^{5}$ Por exemplo, o lançamento, no dia 2 de junho de 2004, pelo Ministério das Cidades, do Brasil Acessível -Programa Brasileiro de Acessibilidade Urbana, programa que visa desenvolver açôes que garantam a acessibilidade aos sistemas de transporte e circulação de vias públicas para as pessoas com restrição de mobilidade.

${ }^{6}$ Para Keleman (1992, p. 10), em seu livro Anatomia Emocional, o corpo é “[...] sede de toda a experiência e a (trans) formação do organismo é vista como uma estratégia da pulsação vital em face a existência”.

${ }^{7}$ A palavra método aqui está sendo usada como: maneira de fazer as coisas; modo de proceder (MÉTODO, 2009).

${ }^{8}$ O Instituto Arte no Dique é uma organização da sociedade civil, sem fins lucrativos, desenvolve atualmente trabalho sóciocultural com a população do Dique da Vila Gilda na Zona Noroeste de Santos, numa das regiōes com maiores índices de vulnerabilidade social da cidade, com uma população de 22 mil habitantes vivendo em condiçôes precárias, em palafitas à beira do mangue, sobre o Rio Bugre (G1, 2014).

${ }^{9}$ Chamamos de coisas os objetos, os materiais, as propostas, as atividades, os diversos mundos possíveis e virtuais.

${ }^{10}$ No artigo "o funcionamento da atenção no trabalho do cartógrafo", Kastrup (2007) baseando-se nos conceitos de atenção flutuante de Freud, de reconhecimento atento de H. Bergson e nas contribuiçôes da vertente fenomenológica das ciências cognitivas contemporâneas define a atençáo cartográfica como concentrada e aberta, caracterizando-se por quatro variedades: o rastreio, o toque, o pouso e o reconhecimento atento.

${ }^{11}$ Ver: Maximino, Petri e Carvalho (2012).

${ }^{12}$ Escolhemos usar o termo práticas estéticas ou invés de artísticas, pois estas podem nos remeter ao campo da grande arte ou da arte para alguns, justamente o que queremos questionar.

${ }^{13}$ Alegria no sentido indicado por Spinoza está relacionada ao aumento de potência, isto é, aumento de nossa força interna e capacidade para agir, aumento do pensamento e da ação. A alegria é caminho de autonomia individual e política. 